\title{
ANALISIS BUDAYA ORGANISASI MENGGUNAKAN ORGANIZATIONAL CULTURE ASSESSMENT INSTRUMENT(OCAI) TERHADAP STASIUN PENGISIAN DAN PENGANGKUTAN BULK ELPIJI (SPPBE) PT. GIGA UTAMA \\ ${ }^{1)}$ Herta Hidayat; ${ }^{2)}$ Dede Aji Mardani \\ 1,2) Prodi Ekonomi Syarih STAI Tasikmalaya \\ Email: ${ }^{1)}$ dedeaji.m@gmail.com
}

\section{How to Cite :}

Hidayat, H., Mardani, D.A. (2020). Analisis Budaya Organisasi Menggunakan Organizational Culture Assessment Instrument(OCAI) Terhadap Stasiun Pengisian Dan Pengangkutan Bulk Elpiji (SPPBE) PT. Giga Utama

\section{ARTICLE HISTORY}

Received [28 Juni 2020]

Revised [20 Juli 2020]

Accepted [31 Juli 2020]

\section{KEYWORDS}

Workload and Work Discipline on Employee Performance

This is an open access article under the $\underline{C C-B Y-S A}$ license

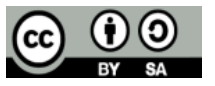

\section{ABSTRAK}

Penelitian ini bertujuan untuk mengetahui pengaruh pemetaan budaya organisasi yang ada saat ini di SPPBE PT. Giga Utama Kecamatan Sukaraja Kabupaten Tasikmalaya. Metode yang digunakan adalah penelitian deskriptif analisis dengan teknik mix method yatiu dengan pengumpulan data melalui studi lapangan yang dilakukan dengan cara wawancara, penyebaran angket, dan Observasi. Alat uji untuk mengolah data yang diperoleh yaitu adalah menggunakan analisis Organizational Culture Assessment Instrument (OCAI) Hasil penelitian ini menunjukkan bahwa budaya organisasi yang yang dipakai saat ini merupakan budaya Market, dan ukuran kesuksessan karyawan dipengaruhi oleh penekanan strategi. Suatu organisasi harus bertransformasi sesuai dengan kondisi yang ada untuk dapat berkembang dengan maju, dan mengetahui tujuan apa yang akan di capai.

\section{ABSTRACT}

This study aims to determine the effect of mapping the organizational culture that exists today at SPPBE PT. Giga Utama, Sukaraja District, Tasikmalaya Regency. The method used is descriptive analysis research with the original mix method technique with data collection through field studies conducted by interview, questionnaire distribution, and observation. The test tool to process the data obtained is using the analysis of the Organizational Culture Assessment Instrument (OCAI). The results of this study indicate that the organizational culture that is used today is Market culture, and the measure of employee success is influenced by strategic emphasis. An organization must transform in accordance with existing conditions to be able to develop forward, and know what goals will be achieved. 


\section{PENDAHULUAN}

Sumber Daya Manusia (SDM) adalah asset utama yang besar sehingga kehadirannya dalam setiap aktivitas organisasi memiliki peranan penting dalam hal ini dalam kemajuan suatu organisasi perusahaan(Rahmi, 2019). Adapun bentuk dan kegiatan organisasi yang dibentuk dipastikan memiliki satu tujuan, padahal setiap manusia yang ada dalam organisasi tersebut memiliki tujuan individual yang berbeda-beda. Darri tujuan yang disatukan menjadi alasan utama dalam berorganisasi. Sistem pelaksanaan budaya organisasi yang sesuai merupakan upaya untuk memacu kinerja karyawan sehingga produktivitas kerja yang dicapai oleh anggota organisasi/karyawan dapat meningkat(Kurniawan, 2018).

Budaya organisasi kini sedang memegang kendali kesuksesan sebuah organisasi. Banyak dari berbagai kalangan baik akademisi, atau praktisi yang konsen terhadap budaya organisasi sampai antisipatif terhadap perubahan yang dapat memenagngkan pasar dalam persaingan(Caliskan \& Zhu, 2019);(David, Valas, \& Raghunathan, 2018)

Perubahan atas persaingan dari luar perusahaan harus menjadikan suatu peluang dan potensi karena perubahan dalam suatu perusahaan adalah suatu keniscayaan dan perubahan terhadap arus permintaan pasar dalam persaingan. (Kasali, 2006). Sebagai perusahaan yanag bergerak dibidang kebutuhan pokok (primer) yaitu isi ulang tabung LPG perusahaan ini diharapkan mamapu untuk bersaing dan berkembang termasuk pada sumber daya manusianya.

Penelitian (Tarlis, 2017)Gaya kepemimpinan dan semangat kerja karyawan memiliki hubungan yang positif, sehingga berpengaruh terhadap semangat kerja karyawan. Penelitian (Firdaus, 2015)Kinerja karyawan dipengaruhi Kontribusi pengaruh komunikasi internal terhadap motivasi kerja pegawai sebesar $63,1 \%$, sisanya $39,1 \%$ dipengaruhi oleh variabel tidak diteliti. Uji hipotesis menunjukkan terdapat pengaruh antara komunikasi internal denagn motivasi kerja.

Penelitian yang telah dilakukan (Umartias \& Djastuti, 2014) terdapat perbedaan budaya organisasi pada pergantian pejabat manajemen. Pada jabatan Excecutive Vice President adalah hierarchy. (Tanadi, 2014);(David et al., 2018)

\section{METODOLOGI}

Penelitian ini menggunakan mix method dengan mengartikulasikan antara penelitain yang mendalam dengan pengolahan data yang riliable. (Juliansyah Noor, 2016), dengan menggunakan variabel bebas dan terikat. Variabel independent sering disebut variabel stimulus, prediktor, antecedent, atau variabel bebas(Zhang, Gill, \& Andrew, 2018). Respondennya adalah seluruh karyawan SPPBE PT. Giga Utama. Dalam metode mix method yang menggabungkan antara dua pendekatan yaitu metode kuantitatif serta dilengkapi dengan data kualitatif (Sugiyono, 2016);(Catherine Cassell and Gillian Symon, 2004). Populasinya adalah seluruh pegawai SPPBE PT. Giga Utama sebanyak 32 orang.

\section{HASIL DAN PEMBAHASAN}

\section{Profil dan Karakteristik Responden}

Karakteristik responden dalam penelitian ini juga terbagi dalam beberapa kategori, yaitu: lama bekerja, usia, dan latar belakang Pendidikan. Deskripsi mengenai karakteristik responden penelitian ini di jabarkan sebagai berikut : 
Tabel 1. Karakteristik Responden Berdasarkan Lama Bekerja, Usia dan Latar Belakang Pendidikan

\begin{tabular}{|c|c|c|c|c|c|}
\hline \multicolumn{2}{|c|}{ Lama Bekerja } & \multicolumn{2}{c|}{ Usia } & \multicolumn{2}{c|}{ Latar Belakang } \\
\hline Tahun & Jumlah & Usia & Jumlah & Pendidikan & Jumlah \\
\hline 1-3 tahun & 8 orang & $18-23$ th & 3 orang & SMP & 1 \\
\hline 3-6 tahun & 9 orang & $23-29$ th & 7 orang & SMA & 27 \\
\hline $6-9$ tahun & 9 orang & $30-35$ th & 8 orang & DIII & 1 \\
\hline$>9$ tahun & 6 orang & $>35$ th & 14 orang & S1 & 3 \\
\hline
\end{tabular}

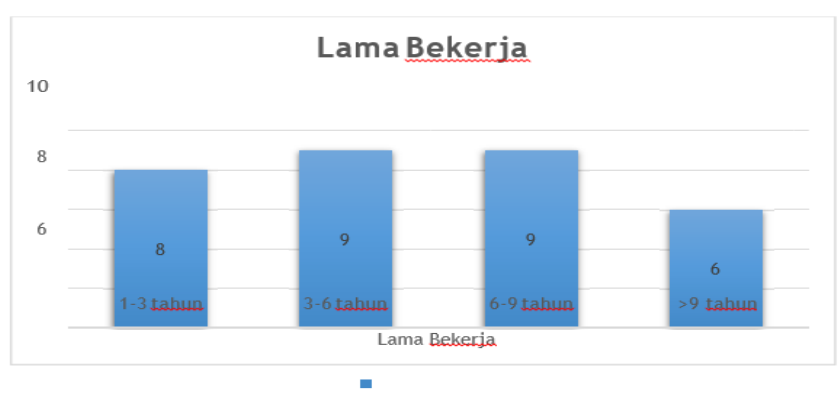

Gambar 1. Chart Karakteristik Berdasarkan Lama Bekerja

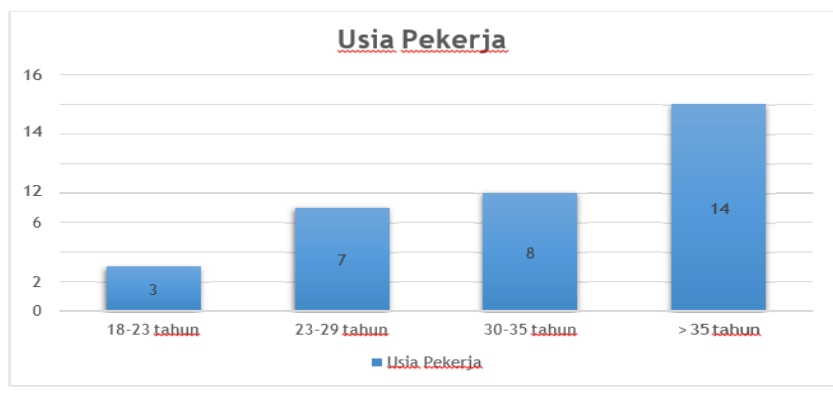

Gambar 2. Chart Karakteristik Berdasarkan Usia Bekerja

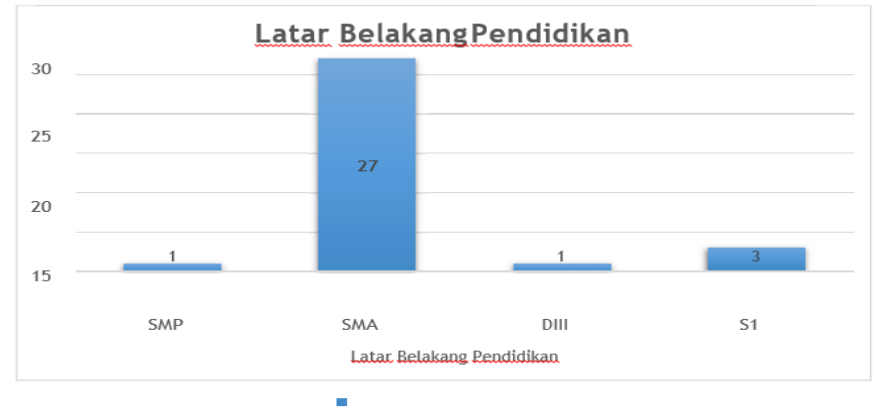

Gambar 3. Chart Karakteristik Berdasarkan Latar Belakang Pendidikan 
Berdasarkan karakteristik responden diatas dapat disimpulkan bahwa responden pada umumnya adalah karyawan SPPBE PT. Giga Utama yang keseluruhannya adalah laki-laki dengan total responden sebanyak 32 orang, selanjutnya responden telah mengabdikan diri di perusahaan SPPBE PT. Giga Utama rata-rata terbanyak yaitu antara rentang 6-9 tahun yaitu sebesar $28 \%$ atau 9 orang pekerja, dan $28 \%$ juga dengan total sama 9 orang yaitu lama bekerja antara rentang 3-6 tahun, sedangkan sisanya 25\% atau 8 orang yang bekerja 1-3 tahun, terakhir 19\% atau 6 orang, lama bekerjanya sudah lebih dari 9 tahun. Sedangkan usia responden memiliki rentang usia (umur para pekerja) yaitu berusia lebih dari 35 tahun sebanyak $44 \%$ atau sebanyak 14 orang pekerja, 25\% atau 8 orang berusia antara 30-35 tahun, 22\% atau 7 orang berusia antara 23-29 tahun, dan terakhir 9\% atau 3 orang berusia antara 18-23 tahun. Untuk tingkat Pendidikan didominasi oleh lulusan SMA atau sederajat yaitu sebesar $85 \%$ pekerja atau sebanyak 27 orang dari total 32 orang. Sedangkan untuk tingkat S1 hanya 9\% atau sebanyak 3 orang, dan yang lulusan DIII serta SMP hanya ada 3\% yaitu 1 orang.

\section{Pemetaan Budaya menggunakan Organizational Culture Assessment Instrument (OCAI)}

a. Budaya Organisasi Yang Paling Dominan Digunakan di SPPBE PT. Giga Utama saat ini.

Berikut merupakan tabel dari hasil pengisian kuisioner yang telah diisi oleh karyawan/para pekerja di SPPBE PT. Giga Utama untuk profil budaya organisasi saat ini:

Tabel 2.Hasil Penelitian Budaya Organisasi Saat Ini

\begin{tabular}{|c|l|c|}
\hline No. & \multicolumn{1}{|c|}{ Pemetaan OCAI } & Profil Budaya Organisasi Saat ini (\%) \\
\hline 1 & Clan & 27.03 \\
\hline 2 & Adhocracy & 21.88 \\
\hline 3 & Market & 27.14 \\
\hline 4 & Hierarchy & 23.96 \\
\hline
\end{tabular}

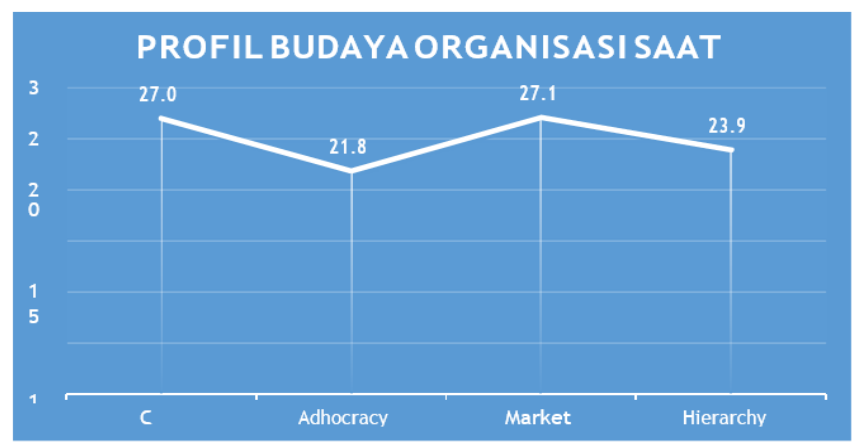

Gambar 4. Chart Profil Budaya Organisasi Saat Ini

Berdasarkan dari perhitungan pada table diatas dapat diketahui bahwa profil budaya organisasi yang dirasakan saat ini oleh seluruh karyawan adalah lebih condong ke budaya Market dengan presentasi sebesar 27,14\% kemudian diikuti dengan budaya Clan yaitu dengan presentasi sebesar 27,03\%, budaya Hierarchy sebesar 23,96\%, dan budaya Adhocracy sebesar $21,88 \%$. Hal ini menunjukan bahwa saat ini organisasi memiliki sistem kekeluargaan dan sistem kompetensi yang seimbang, namun budaya Market lebih dominan sehingga lebih 
menitik beratkan pada hubungan kerjasama eksternal dengan gambaran organisasi adalah memiliki sikap kompetisi yang tinggi.

\section{b. Budaya Organisasi Yang Diharapkan Dimasa Akan Datang SPPBE PT. Giga Utama}

Dapat dilihat tabel dari hasil pengisian kuisioner yang telah diisi oleh karyawan/para pekerja di SPPBE PT. Giga Utama:

Tabel 3. Hasil Penelitian Profil Budaya Organisasi Yang Diharapkan

\begin{tabular}{|c|l|c|}
\hline No. & \multicolumn{1}{|c|}{ Pemetaan OCAI } & Profil Budaya Organisasi Yang Diharapkan (\%) \\
\hline 1 & Clan & 30.81 \\
\hline 2 & Adhocracy & 25 \\
\hline 3 & Market & 17.89 \\
\hline 4 & Hierarchy & 26.3 \\
\hline
\end{tabular}

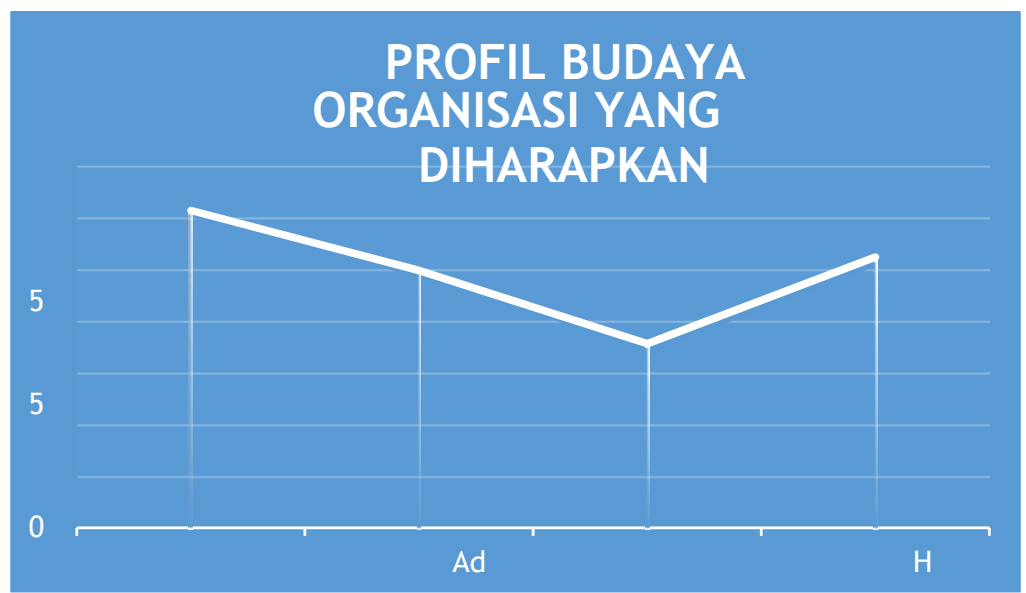

\section{Gambar 5. Chart Profil Budaya Organisasi Yang Diharapkan}

Persepsi profil budaya organisasi yang diharapkan oleh seluruh karyawan yaitu budaya Clan, terlihat sangat besar dominannya dibandingkan dengan profil budaya organisasi lainnya yaitu sebanyak 30,81\% dan budaya Hierarchy memiliki nilai 26,3\% sedangkan untuk Adhocracy $25 \%$ dan terahir yaitu budaya organisasi Market sebesar 17,89\%. Hal ini menunjukan budaya organisasi yang diharapkan seluruh karyawan adalah budaya organisasi yang lebih meningkatkan dan mengedepankan kekeluargaan sehingga adanya pengembangan SDM (Sumber Daya Manusia) yang baik dan juga adanya peningkatan pada sistem birokrasi organisasi untuk menjadi lebih baik lagi.

\section{c. Perbandingan Profil Budaya Organisasi Saat ini dan Yang Diharapkan.}

Berikut pengolahan data hasil dari kesimpulan persepsi seluruh karyawan berdasarkan profil budaya organisasi saat ini dan yang diharapakan, yaitu: 
Tabel 4. Perbandingan Profil Budaya Organisasi Saat Ini dan Yang Diharapkan

\begin{tabular}{|c|l|l|l|}
\hline No. & \multicolumn{1}{|c|}{ Pemetaan OCAI } & $\begin{array}{c}\text { Profil Budaya Organisasi Saat } \\
\text { Ini (\%) }\end{array}$ & $\begin{array}{c}\text { Profil Budaya } \\
\text { Organisasi Yang } \\
\text { Diharapkan (\%) }\end{array}$ \\
\hline 1 & Clan & 27,03 & 30,81 \\
\hline 2 & Adhocracy & 21,88 & 25 \\
\hline 3 & Market & 27,14 & 17,89 \\
\hline 4 & Hierarchy & 23,96 & 26,3 \\
\hline
\end{tabular}

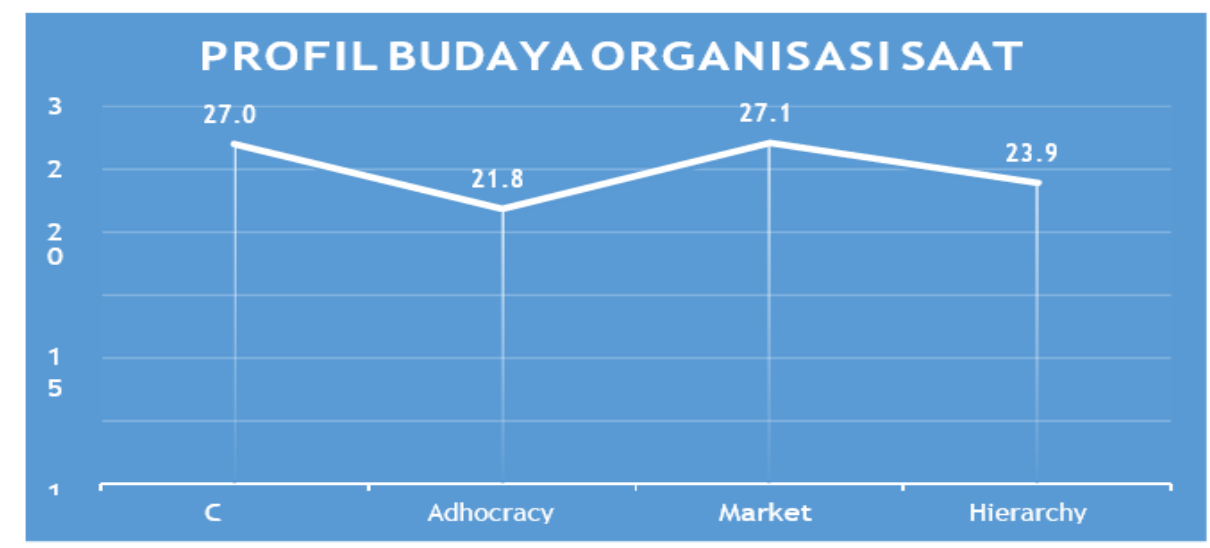

Gambar 6. Chart Perbandingan Profil Budaya Organisasi Saat Ini dan Yang Diharapkan

Berdasarkan pengolahan data pada table dan gambar diatas maka dapat dilihat dari keseluruhan karyawan untuk saat ini merasakan budaya Market dan budaya Clan hal ini ditunjukkan dari total presentasi sebesar 27,14\% untuk budyaa Market dan 27,03 untuk budaya Clan. Hal ini menunjukkan saat ini organisasi ataupun perusahaan memiliki sistem kekeluargaan tetapi mengedepankan kompetensi yang ketat dan tinggi.

Hal ini berbeda dengan apa yang diharapkan oleh seluruh karyawan untuk kedepannya, karyawan menginginkan adanya penguatan untuk budaya Clan, Hierarchy, dan Adhocracy serta untuk budaya Market berharap adanya penurunan. Para karyawan mengharapkan adanya peningkatan budaya Clan dari $27,03 \%$ menjadi $30,81 \%$ itu menunjukan bahwa karyawan kedepannya ingin membentuk sebuah perusahaan yang kuat disertai adanya dorongan untuk pengembangan moral karyawan serta kerja sama tim yang kuat. Hal ini juga sejalan dengan adanya peningkatan pada budaya Hierarchy yang menunjukan adanya peningkatan dari $23,96 \%$ menjadi $26,3 \%$ hal ini menunjukan bahwa sistem perusahaan yang ada saat ini sedikit lemah sehingga diperlukan adanya perubahan sistem yang semakin baik, yaitu diharapkannya adanya sebuah struktur yang baik dan rapi dalam organisasi(Suderman, 2012). Dan untuk budaya Adhocracy diharapkan juga untuk meningkat dari yang dirasakan saat ini dibandingkan yang diharapkan kedepannya yaitu dari $21,88 \%$ saat ini menjadi $25 \%$ yang diharapkan kedepannya, maka hal ini diharapkan adanya eksperimen dan inovasi yang meningkat dari pada sebelumnya. Sedangkan yang mengalami penurunan adalah budaya Market dengan penurunan yang cukup signifikan, artinya budaya Market diharapkan tetap dikembangkan akan tetapi agak dikurangi penekanannya dimasa yang akan datang, sehingga bisa ditambah dengan nilai-nilai yang ada pada budaya Clan.

Profil budaya clan yang dominan diharapkan oleh karyawan merupakan suatu kondisi dimana perusahaan merupakan tempat kerja yang nyaman seperti layaknya keluarga, adanya 
kebersamaan kuat diantara para karyawannya. Figur pemimpin yaitu pemimpin yang dapat membimbing, memfasilitasi, memberikan pelajaran dan berperan sebagai penasehat bahkan seperti orang tua(Fralinger \& Olson, 2007). Kerjasama, partisipasi, dan usaha mempertemukan pendapat adalah hal yang dianggap penting. Hal ini dapat dilihat dari dimensi yang menonjol pada budaya clanyaitu karakteristik dominan, gaya kepemimpinan, manajemen karyawan, dan ukuran kesuksesan. Budaya hierarchyyang diharapkan karyawan yaitu sutu kondisi dimana gaya manajemen dicirikan dengan rasa aman dalam bekerja, kecocokan, keterprediksian dan adanya hubungan yang stabil. Hal ini dapat dilihat dari dimensi yang paling menonjol pada budaya hierarchy yaitu manajemen karyawan.

\section{IMPLIKASI BAGI MANAJEMEN}

Hasil penilailan budaya perusahaan dengan menggunakan instrumen OCAI menunjukkan bahwa para pimpinan dan karyawan berpendapat budaya yang mereka rasakan saat ini yaitu kombinasi antara budaya market dan clan(Hansen, 2018). Mereka menginginkan di masa yang akan datang dilakukan peningkatan budaya clan dan pengurangan budaya market. Peningkatan budaya clan dilakukan terutama pada dimensi manajemen karyawan dan ukuran kesuksesan. Pengurangan budaya market terutama dilakukan pada dimensi manajemen karyawan dan penekanan strategi(Aydın, 2018).

Sebagai implikasi dari hal tersebut, perusahaan perlu meningkatkan kompetensi manajerial yang sesuai yang meliputi :

1. Managing the development of others (mengelola pegembangan sumber daya manusia), yaitu mengelola dan memacu kinerja karyawan dengan memberikan kesempatan pada jenjang karir

2. Managing interpersonal relationship (mengelola hubungan antar personal), yaitu dengan konsep mendengar dan menerima selur masukan dari para karyawannya serta memberikan solusi.

3. Managing team (mengelola tim), yaitu membuat networking anta pekerja sehingga terbentuk budaya kuat saling keterkaitan dengan tujuan yang sama.

\section{DAFTAR PUSTAKA}

Aydin, B. (2018). The role of organizational culture on leadership styles. MANAS Sosyal Araştırmalar Dergisi, 7(1), 267-280.

Caliskan, A., \& Zhu, C. (2019). Organizational Culture Type in Turkish Universities using OCAI: Perceptions of Students. Journal of Education Culture and Society, 10(2), 270292.

Catherine Cassell and Gillian Symon. (2004). Essential Guide To Qualitative Methods In Organizational Research. California: SAGE Publications India Pvt Ltd.

David, S. N. J., Valas, S., \& Raghunathan, R. (2018). Assessing Organization Culture-A Review on the OCAI Instrument. In International Conference on Management and Information Systems September (Vol. 21, p. 22).

Firdaus, M. R. (2015). Pengaruh Komunikasi Internal Terhadap Motivasi Kerja the Influence of Internal Communication on Work Motivation, 2(2), 2164-2175.

Fralinger, B., \& Olson, V. (2007). Organizational culture at the university level: A study using the OCAI instrument. Journal of College Teaching \& Learning (TLC), 4(11).

Hansen, M. (2018). Cultivating change: The relationship between organizational culture, leadership style and communication style with organizational change.

Juliansyah Noor, S. E. (2016). Metodologi Penelitian: Skripsi, Tesis, Disertasi \& Karya Ilmiah. Prenada Media. 
Kasali, R. (2006). Adverising that Sells. Gramedia pustaka Utama, Jakarta.

Kurniawan, P. (2018). Pengaruh Motivasi Dan Disiplin Kerja Terhadap Produktifitas Kerja Karyawan Pada PT. Daya Perkasa. Jurnal Mandiri, 2(2), 315-330.

Rahmi, D. M. (2019). Investasi Modal Manusia Dalam Pembangunan Ekonomi Perspektif Islam. Jurnal Manajemen Dan Bisnis Indonesia, 5(1), 55-64.

Suderman, J. (2012). Using the organizational cultural assessment (OCAI) as a tool for new team development. Journal of Practical Consulting, 4(1), 52-58.

Sugiyono, M. P. P. (2016). Pendekatan Kuantitatif, Kualitatif, dan R \& D (cetakan ke-23). Bandung: Alfabeta.

Tanadi, M. (2014). Pemetaan Budaya Organisasi di PT. Wisata Dewa Tour dan Travel tahun 2013. E-Journal Graduate Unpar, 1(1).

Tarlis, A. (2017). Pengaruh Gaya Kepemimpinan Terhadap Semangat Kerja Karyawan Pada Bank Mandiri Cabang Langsa. Pengaruh Gaya Kepemimpinan, 2(2), 1-20.

Umartias, M., \& Djastuti, I. (2014). Pemetaan Budaya Organisasi Menggunakan Organizational Culture Assessment Instrument (Ocai) Pada PT Kereta Api Indonesia Daerah Operasional 4 Semarang. Diponegoro Journal of Management.

Zhang, M., Gill, S., \& Andrew, S. (2018). Outlines and Outliers: A mix-method study of garment silhouette and the ageing body. In 91st Textile Institute World Conference: Integrating Design with Sustainability. 